\title{
Community Violence as Psychosocial Stressor: The Case of Childhood Asthma in Boston
}

\author{
Gonzalo Bacigalupe $^{1,2}$, Takeo Fujiwara ${ }^{3,4}$, Sabrina Selk ${ }^{3}$, Meghan Woo ${ }^{3}$ \\ ${ }^{1}$ Department of Counseling Psychology, University of Massachusetts Boston, Boston, USA; ${ }^{2}$ Department of Psychology, University \\ of Deusto and Basque Foundation for Science, Ikerbasque, Bilbao, Spain; ${ }^{3}$ Department of Society and Human Development and \\ Health, Harvard School of Public Health, Boston, America; ${ }^{4}$ Department of Psychosocial Medicine, National Center for Child Health \\ Development, Tokyo, Japan. \\ Email: gonzalo.bacigalupe@umb.edu
}

Received February $3^{\text {rd }}$, 2010; revised February 20 ${ }^{\text {th }}, 2010$; accepted February $20^{\text {th }}, 2010$.

\begin{abstract}
Childhood asthma is a critical public health problem of urban centers in the United States and other industrialized nations. Population-based and laboratory research studies indicate that psychosocial stress differentially affects asthma expression. Witnessing or experiencing community violence is a psychosocial stressor that results in long-term biological changes that may in turn contribute to asthma morbidity. This is a review of the literature that examines the exposure to violence as a psychosocial stressor that is independently associated with asthma morbidity even after adjustment for income, housing, and other adverse life events. In addition to acting as a physiological trigger for the disease, community violence can also impact health behaviors and exposure to other unknown environmental risk factors. This connection leads the authors to suggest that reducing violence and the amelioration of its impact has implications beyond public health. The City of Boston in Massachusetts serves as the context to contextualize a series of recommendations that may ameliorate and/or prevent asthma incidence and prevalence. The reduction of poverty, unemployment, substandard housing, and high crime/violence rates can have significant health implications for children asthma and a decline on asthma hospitalization.
\end{abstract}

Keywords: Psychosocial Stress, Violence, Asthma, Public Health

\section{Introduction}

Our current understanding of what causes asthma continues to remain elusive [1]. There is, however, an increasing recognition of the relationship between psychosocial stress and asthma incidence and prevalence. We examine, first, this relationship, more specifically social violence, as a primary environmental exposure for asthma morbidity. And second, we discuss policy changes that may prevent and ameliorate asthma prevalence in urban settings including directions for future research. Childhood asthma is the subject of innumerous research studies. However, there are still many unknowns about its etiology and how environmental factors contribute to the onset and periodic episodes of this disease. Epidemiological research, meanwhile, demonstrates a disproportionate burden of disease amongst children of low socioeconomic position [2-8]. Furthermore, specific environmental exposures, such as violence, affect susceptible populations and contribute to asthmatic attacks [8-10]. This growing body of evidence, although still preliminary, provides an alternative explanation through which psychosocial stress as a result of exposure to violence, acts as a primary exposure to elicit asthma symptoms. Research into this phenomenon may help to explain the higher burden of disease amongst children living in disadvantaged neighborhoods and provide insight into interventions to combat this growing trend.

\section{Epidemiology of Asthma}

\subsection{Burden of Asthma}

Childhood asthma is prevalent in all major urban centers in the United States and other industrialized nations [1,11]. In 2003, 30 million or $10.4 \%$ of Americans had asthma. 20 million had had an asthma attack in the previous year. 9 million or $12.5 \%$ of children under the age of 18 in the U.S. had an asthma attack in the previous year. Current trends indicate that prevalence rates for current asthma increased more than double from 1980 to 2003. The most substantial increase occurred among children ages 0 to 4 years and ages 5 to 14 years. This increasing trend in rates was evident across race, sex, and age [12]. 
The medical services used to treat asthma result in over 10.8 million physician visits, over 478,000 hospitalizations, 2 million emergency room visits, and about 28 million missed school days annually [13]. Direct health care expenditures such as physician visits, medications and other interventions are estimated to be US\$ 7.4 billion. About US\$ 3.2 billion of those direct costs are spent on asthma care for children [14]. Indirect costs such as decreased worker productivity, days lost from work by adults who have asthma or care for children with asthma, and other losses are an estimated $\$ 5.3$ billion [15].

In Massachusetts, the first pediatric asthma surveillance report released in 2004 found that has $9.2 \%$ of children in school diagnosed with asthma. District level prevalence varies from 2.7 to $16.2 \%$, with prevalence as high as $30 \%$ in some schools [16]. This implies asthma prevalence correlates with district level factors such as physical or social environment. The Prevalence of active asthma in the city of Boston was higher than the Massachusetts average: one in seven, or $14 \%$ of children attending school had active asthma the year 2004 with a disproportionate burden of disease amongst students living in disadvantaged neighborhoods. Children with asthma average three times as many absences and use significantly more health services than other children. An estimated US\$ 77 million a year are spent for both direct and indirect costs associated with childhood asthma in Massachusetts [16].

\subsection{Children in Disadvantaged Neighborhoods: A Vulnerable Population}

Asthma prevalence and morbidity rates have drastically risen in the United States over the past two decades. Children living in disadvantaged neighborhoods have been found to be particularly vulnerable to higher asthma morbidity rates. Neighborhood disadvantage is characterized by the presence of a number of community-level stressors including poverty, underemployment, racial discrimination, environmental inequity, limited social capital, sub-standard housing, high crime and violence rates [9]. Racial and income disparities in asthma morbidity have been consistently reported with higher rates of asthma hospitalization and mortality in neighborhoods with low median incomes and a high prevalence of minority populations [17]. The health problems of these disadvantaged populations are not likely to be solved without understanding the potential role of such social determinants of health [18].

In the United States today, rates of asthma morbidity are highest among minority children, particularly those who reside in urban areas of low socioeconomic position. Income and poverty status has been found to be highly related to the number of asthma attacks a child reported in the last 12 months. 5.5\% of children who were not poor reported having an asthma attack in the last 12- months compared to $8.0 \%$ of poor children [19]. In Boston, childhood asthma morbidity rates are also highest in disadvantaged neighborhoods with a high percent of black and Latino residents and low socioeconomic status [20]. In contrast, neighborhoods with higher median income had much lower rates of hospitalization.

\section{Psychosocial Stress: An Environmental Exposure}

\subsection{Psychosocial Stress and Asthma}

Most research attributes differences in asthma morbidity to variation in socioeconomic position. Disparities in asthma outcomes, however, cannot be explained by socioeconomic factors alone. Geographic variation has been found in asthma morbidity among cities and neighborhoods of similar socioeconomic status [9]. Growing evidence from population-based and laboratory studies indicate exposure to psychosocial stress differentially affects asthma expression [21]. These findings suggest that exposure to psychosocial stress puts children at greater susceptibility to asthma morbidity by disturbing the regulation of the hypothalamic-pituitary-adrenal (HPA) system. In this framework, psychosocial stress can be conceptualized as an environmental exposure that can enter the body resulting in long-term biological changes that may contribute to asthma morbidity [22].

Research shows that psychosocial stress can also exacerbate asthma symptoms by making the lungs more susceptible to other environmental hazards. For instance, a lowered immune response caused by stress has been shown to increase rates of respiratory infections [23]. Stress can also influence behaviors which may lead to an increase in a child's exposure to potential risks such as indoor allergens and second-hand smoke, or by making children more vulnopin (Figure 1). Researchers are just beginning to tease out these intertwining pathways. The following section presents the current state of research and the known biological impact of psychosocial stress on asthma morbidity including violence.

\subsection{The Biological Impact of Psychosocial Stress}

The idea that emotions are important to asthma exacerbation is not new. References to this hypothesized connection in popular culture and the scientific literature are common. However, it is only in recent years that scientists have been able to identify and to rigorously test theories of how exogenous events are translated into physiological responses. In this case, how psychosocial stress can lead to an asthma attack. Current research is examining the ways that psychosocial stress acts as a social pollutant that can increase morbidity and exacerbate symptoms in children with asthma-a heuristic mode for this pathway is shown in Figure 2. 


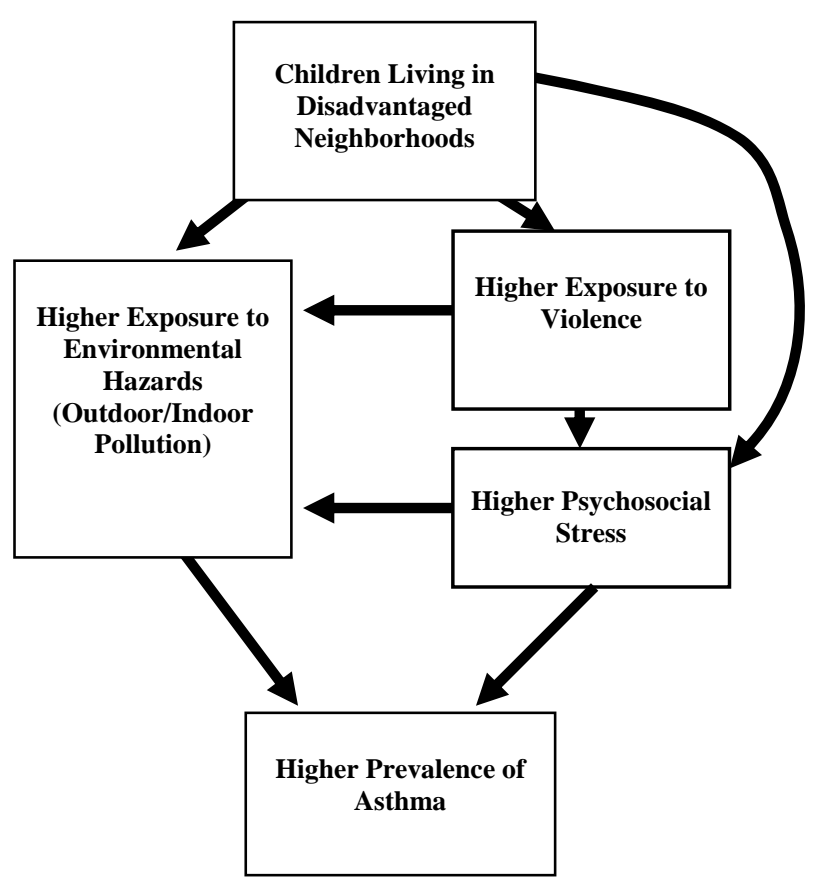

Figure 1. Proposed framework: pathways between psychosocial stress, neighborhood disadvantage and asthma
In humans, the primary source of physiological response to stress stems from activation of the HPA axis. This stimulation begins a cascading release of neurotransmitters, neuropeptides, and hormones that stimulate a sympathetic response to the perceived stressor. While this is generally a beneficial reaction that helps prepare the body to react to negative stimuli, research has shown that an overactivation of the HPA axis, through chronic stress or acute stressors, can have negative impacts on the body.

In the case of asthma, it is believed that the deleterious physical effects are mediated at least in part by the shared pathway of activation of the autonomic control of the airways in both asthma and stress responses. This overlap can be used to explain how the parasympathetic stress response might influence lung tone. Studies examining exposure to stressors have used vagal reactivity in response to stress as a measure of emotion induced airway constriction [24]. The mechanism suggested by this relationship is that the presence of an acute stress event will trigger a parasympathetic response including vagal activation and a corresponding rapid release of catecholamine leading to airway constriction. However, this is not the only way that stress has been implicated in exacerbating asthmatic symptoms [25].

The second physiological component of an asthma attack

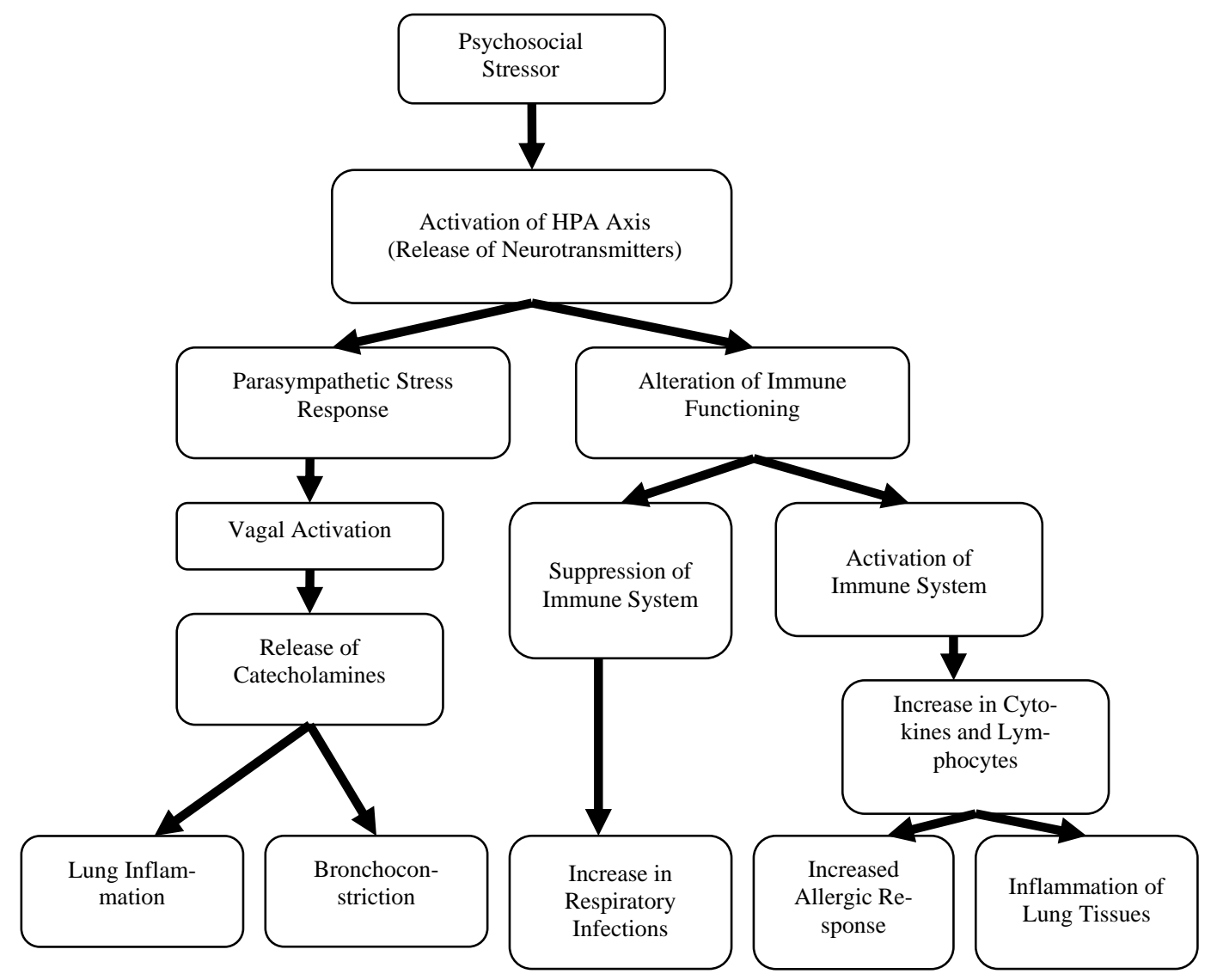

Figure 2. Hypothesized pathways: biological impact of psychosocial stress \& asthma 
is believed to be more closely associated with immune function. Stress induced alterations in immune response can be complex and may include both activation and suppression of the immune system. Some suggest that this alteration in lymphocyte creation may be an important component to the etiology of asthma in children raised in stressful environments [26]. These immune alterations are especially critical in the early development of a child's immune system when the Th2 polarization of their immune system and Th2 reactivity to allergens develops $[27,28]$. Although the direct role of stress on Th2 levels is still being investigated, there is evidence that parental report of life stress is associated with onset of wheezing in children less than one year of age [29].

\subsection{Violence: A Primary Psychosocial Stressor}

Children living in disadvantaged neighborhoods are at higher risk for asthma morbidity largely resulting from greater exposure to psychosocial stressors. We have characterized psychosocial stress as an environmental exposure that directly impacts the physiological expression of asthma. A clearer understanding of the most relevant sources of psychosocial stress that impact asthma morbidity is needed to adequately address interventions and policy initiatives improving psychosocial stress exposure in this vulnerable population. The literature to date has primarily focused on exposure to community violence as the principal psychosocial factor impacting asthma morbidity among children living in disadvantaged neighborhoods $[9,26]$. For the purposes of this paper we characterize community violence as direct exposure through victimization or through witnessing of violence. We primarily refer to violence that occurs outside the home rather than domestic violence, although we acknowledge exposure to domestic violence could have similar effects on asthma morbidity.

The psychosocial stressors associated with neighborhood disadvantage are numerous; however, the prevalence of chronic community violence is a specific and extreme stressor confronting the urban poor [26]. Likewise, the prevalence of high crime and violence is a critical component defining neighborhood disadvantage. As a result, exposure to violence has a direct impact on asthma morbidity rather than simply serving as a marker for low socioeconomic position. It has been independently associated with asthma morbidity even after adjustment for income, housing problems, and other adverse life events [30].

Certain populations face a greater deleterious effect of stress when facing daily life experiences that are unpredictable or uncontrollable [31]. This is critically important to asthma morbidity in disadvantaged neighborhoods given that living in a violent community has been associated with a chronic pervasive atmosphere of fear and the perceived threat of violence. Children and families ex- posed to community violence are more likely to view their world as being out of their control and to suffer more harmful effects from stress [26-30].

Community violence is pervasive. Studies have demonstrated that children living in urban disadvantaged neighborhoods are exposed to high rates of violence. More than $46 \%$ of children and adolescents in the U.S. reported being the direct victim of violence and over $60 \%$ reported having been exposed to community violence [32]. In an inner-city cohort in Chicago, Ilinois, $42 \%$ of children ages $7-13$ had seen someone shot while $37 \%$ had seen someone stabbed [33]. In Boston, one study examined the prevalence of witnessing violence among children ages 1-5 from the pediatric primary care clinic at Boston City Hospital. The researchers found that $10 \%$ of children witnessed a knifing or shooting; $18 \%$ witnessed shoving, kicking, or punching; and 47\% heard gunshots [34]. Similarly, in a national cohort sample from large U.S. cities, children had a 2 fold increased risk of asthma when exposed to interpersonal violence at home [3].

\subsection{Impact of Exposure to Violence on Asthma}

Violence affects asthma morbidity through many pathways. In addition to acting as a physiological trigger for the disease, community violence can also impact health behaviors and exposure to other unknown environmental risk factors [9]. For example, parents and caretakers who are worried about their children's safety may restrict outdoor activities leading to a greater exposure to indoor allergens. Given that the degree of housing disrepair has been associated with increased cockroach allergen levels (a known risk factor for increased asthma), children who live in disadvantaged neighborhoods and must stay indoors have higher rates of asthma morbidity [35]. Keeping children indoors may also restrict their ability to develop support networks. Additionally, it has been suggested that fear of crime fosters a distrust of others. Both of these factors can lead to social isolation and a diminishment of stress buffering factors such as social networks [26].

This exposure may also impact the adoption of coping behaviors by household members such as smoking, another known trigger for asthma. One study examining increased rates of smoking in African American households found that the strongest predictor of smoking was a report of high stress levels [36]. In a study of tobacco use among adolescents, smoking was strongly associated with adverse childhood experiences. This indicates nicotine may be adopted as a pharmacological coping device for the negative emotional, neurobiological, and social effects of adverse childhood experiences [37].

Finally, a violent environment may also impact compliance to asthma treatments and medical follow-up. Caregivers may fear making a trip to a pharmacy or me- 
dical provider for treatment due to fear of personal safety in a violent neighborhood. Additionally, pharmacies may not stay open at night in high crime areas, limiting immediate or emergency access to medication. As mentioned previously it has been suggested that families who live in a violent environment are more likely to feel like their world is out of control. Helplessness has been linked to depression, which may limit the caretaker's ability to buffer the detrimental effects of community violence in the lives of their children [38]. Caretakers living in violent communities frequently express a sense of helplessness and frustration in their inability to protect their children.

\section{Policy Recommendations}

Prioritizing the reduction of psychosocial stressors, here described as community violence, in vulnerable neighborhoods introduces a beneficial externality: the reduction of asthma morbidity among children. This morbidity reduction, in turn, would bring other forms of economic, social, and health benefits that are directly and indirectly related to the disease under study. In Boston and other urban settings, attempts at controlling violence have always been accompanied by large community initiatives. In conjunction with reducing psychosocial stress through violence prevention and control measures, making health care accessible is a core component in reducing other forms of psychosocial stress. Enhancing quality health care accessibility for children with asthma and reduction of known indoor environmental exposures are indispensable in the long-term control of asthma.

Asthma morbidity is the result of a complex interplay of influences operating at several levels, including the individual, the family, and the community. Similarly, decisions regarding policies and programs that would reduce violence and the amelioration of its impact have implications beyond public health. Often policies that address violence prevention and control and health care access and quality operate in distinct legislative and regulatory worlds. To reformulate these policies into an integrated process, legislators should include psychosocial stressors like neighborhood violence in venues beyond the realm of law enforcement.

We recognize the complexity of preventing violence and asthma as well as the need for a variety of policies in the realm of environmental justice, human services, and law enforcement. However, none of these factors alone will suffice. For example, reinforcing police presence may not necessarily reduce the prevalence of psychosocial stress since police presence by itself may increase community stigma and fear. Our recommendations recognize the need for intersectorial policies to simultaneously address exposure to violence as well as prevention and treatment of asthma morbidity. There is strong evidence for violence acting as a significant psychosocial stressor however the exact mechanisms remain unclear introducing uncertainty in the risk analysis [39]. The precautionary principle [40] indicates that policy makers should develop the means to include considerations of the role that psychosocial stress plays on asthma morbidity within governmental and social policy as well as through recommendations to individuals [18]. We have categorized the recommendations under three areas: research and information, community participation, and public health initiatives.

\subsection{Research \& Information}

Exposure to violence as a risk to the health of children has been the source of a growing number of research initiatives. These are promising activities but more research is needed to assess the specific exposure pathway and its connection with the known factors that determine health and health care disparities in asthma morbidity. At the present, we are only able to hypothesize that violence acts as a compounding or additive mechanism in making children more vulnerable to the impact of environmental pollutants (indoor and outdoor)-likely through its impact on the health seeking behavior of parents and children under treatment.

In addition to more methodologically sound research to identify the morbidity mechanisms; there is also a need for greater data of asthma morbidity amongst children as well as information on trends over time. To fill this need, the City of Boston should be a leader in efforts to establish a centralized state asthma data registry. This registry should include a system of surveillance by which psychosocial stressors assessment is routinely integrated into the treatment of children arriving with asthma crises to emergency rooms and local community health centers.

\subsection{Community Participation}

The City of Boston is experiencing resurgence in the number of homicides and other forms of social violence despite previous successful efforts at reducing its prevalence. There is a rich opportunity to link the renewed efforts at preventing and controlling violence with an awareness and identification of the psychosocial stressors directly linked to asthma morbidity that offers a significant opportunity to strengthen those efforts. These efforts may include: incorporating asthma morbidity prevention as another dimension in the Boston strategies to confront neighborhood violence, i.e., Boston Strategic MultiAgency Response Teams, Youth Center Initiatives, among others [41]; creating collaborative research and intervention initiatives with housing collaborative health initiatives to incorporate psychosocial stress as part of the surveillance and educational intervention activities engaging with community participants in the integration of evidence based knowledge into program efforts; incor- 
porating the psychosocial stress agenda into the Asthma Planning Collaborative Initiative which has as a goal to develop a Massachusetts State Plan for Asthma.

\subsection{Public Health Initiatives}

Asthma is one of many chronic diseases in the United States in which disparities in treatment and access to care have been documented [42]. The City of Boston as part of its plans which include reducing health disparities [43] could provide further funding for: community based participatory research [44-46] with the goal of developing strategies to reduce violence in urban neighborhoods with high incidence of asthma morbidity; research projects that use a positive deviance model $[47,48]$ to investigate how some families and community groups have been able to develop effective strategies and positively cope despite the witnessing of social violence in their neighborhoods; curricular initiatives to develop educational materials for others to learn from those community research experiences.

Second, in addition to these community research initiatives, the healthcare needs of patients need to be addressed. Social violence inhibits the ability of parents of ensuring the safety of their children and leading to emotionally unavailability due to fear and trauma [49]. These healthcare needs could be satisfied via the development of a comprehensive program to support and empower parents as the key factor in developing resilience and mediate the effects of children's exposure to violence; designing psychosocial and community interventions that help parents to reduce the psychological strain produced by a sense of lack of control and agency in their lives; fostering the development of community cohesion and trust to provide parents with a social support network that counteracts the deleterious effects of social violence; collaborating with child welfare institutions and collaborative family initiatives to assess and strengthen appropriate prevention and treatment of asthma morbidity among the children served by these programs; collecting information about asthma morbidity from programs that address the psychological needs of children that have identified as having witnessed or victimized by violence in their homes and/or neighborhoods.

Third, universal health care coverage is synergetic with recommendations directly addressing health care access and quality in the case childhood asthma. As part of these efforts, medical insurers would include as part of their plans asthma medical supplies and education specialists providing consistent education, expertise and support for patient to successfully identify and manage asthma; and, ameliorating the transportation and other health care access barriers. Examples of these efforts include a program like a roving clinic on wheels for asthmatic school children to provide a comprehensive asthma management strategy [50,51].
Policies that reduce poverty, unemployment, substandard housing, and high crime/violence rates may have significant health implications for children and ultimately have a direct impact on asthma hospitalization [2]. Similarly, policies that regulate outdoor and indoor air pollution would also affect asthma morbidity. In addition to direct impacts on community residents, crime and violence (or the lack thereof) can be used as indicators of collective well-being and social cohesion within a community. Furthermore, the conditions known to be associated with violence exposure are related to having experienced stress [52,53], and chronic violence exposure has been conceptualized as a pervasive environmental stressor imposed on already vulnerable populations $[4,10]$ including asthma $[5,8]$.

\section{Conclusions}

Asthma is a highly prevalent and increasing health challenge for urban neighborhoods across the nation and within Boston. Exposure to community violence creates high levels of psychosocial stress in neighborhoods, which are associated with a higher burden of childhood asthma. The theory of embodiment suggests that the body can often tell a story about the conditions of our lives [54,55]. We argue that asthma is the embodiment of the exposure to the environmental pollutant of violence in children's lives. There are many pathways through which this experience acts upon the body. Lack of social support, fear and stigma, greater exposure to indoor pollutants and allergens, as well as impacts on health behaviors are often part of living in environments where exposure to violence is high. However, it is violence itself that acts as a primary predictor of the psychosocial stress that is translated into biological changes in the respiratory and immune systems of children living in these neighborhoods. While there are uncertainties about the exact mechanisms behind this relationship, the precautionary principle should guide our actions towards making policies to protect the health of children now.

Based on the evidence and the burden of disease, we analyzed potential interventions that include: continued research and data gathering; increasing community participation in measures to combat violence and revitalize neighborhoods; and initiation of public health programs to address both violence prevention and decreasing barriers to asthma care and treatment. True change in asthma morbidity can only occur when the full context in which children live their lives is considered, and this must include a realization of the important role that psychosocial stress and violence play in this disease.

\section{REFERENCES}

[1] M. I. Asher, "Recent Perspectives on Global Epidemiology of Asthma in Childhood," Allergologia et Immunopathologia, 2010. 
[2] D. R. Williams, M. Sternthal and R. J. Wright, "Social Determinants: Taking the Social Context of Asthma Seriously,” Pediatrics, Vol. 123, Suppl. 3, 2009, pp. 174184.

[3] S. F. Suglia, M. B. Enlow, A. Kullowatz and R. J. Wright, "Maternal Intimate Partner Violence and Increased Asthma Incidence in Children: Buffering Effects of Supportive Caregiving," Archives of Pediatrics and Adolescent Medicine, Vol. 163, No. 3, 2009, pp. 244-250.

[4] S. V. Subramanian and M. H. Kennedy "Perception of Neighborhood safety and Reported Childhood Lifetime Asthma in the United States (U.S.): A Study Based on a National Survey," PLoS One, Vol. 4, No. 6, 2009, p. e6091.

[5] T. J. Marin, E. Chen, J. A. Munch and G. E. Miller, "Double-Exposure to Acute Stress and Chronic Family Stress is Associated with Immune Changes in Children with Asthma," Psychosomatic Medicine, Vol. 71, No. 4, 2009, pp. 378-384.

[6] H. Rhee, M. J. Belyea and K. S. Elward, "Patterns of Asthma Control Perception in Adolescents: Associations with Psychosocial Functioning," Journal of Asthma, Vol. 45, No. 7, 2008, pp. 600-606.

[7] Y. Peeters, S. N. Boersma and H. M. Koopman, "Predictors of Quality of Life: A Quantitative Investigation of the Stress-Coping Model in Children with Asthma," Health Qual Life Outcomes, Vol. 6, No. 24, 2008.

[8] R. T. Cohen, G. J. Canino, H. R. Bird and J. C. Celedon, "Violence, Abuse and Asthma in Puerto Rican Children," American Journal of Respiratory and Critical Care Medicine, Vol. 178, No. 5, 2008, pp. 453-459.

[9] R. J. Wright, H. Mitchell, C. M. Visness, et al. "Community Violence and Asthma Morbidity: The Inner-City Asthma Study," American Journal of Public Health, Vol. 94, No. 4, 2004, pp. 625-632.

[10] S. V. Subramanian, L. K. Ackerson, M. A. Subramanyam and R. J. Wright, "Domestic Violence is Associated with Adult and Childhood Asthma Prevalence in India," International Journal of Epidemiology, Vol. 36, No. 3, 2007, pp. 569-579.

[11] P. Ellwood, M. Asher, R. Beasley, T. Clayton and A. Stewart, "The International Study of Asthma and Allergies in Childhood (ISAAC): Phase Three Rationale and Methods," International Journal of Tuberculosis and Lung Disease, Vol. 9, No. 1, 2005, pp. 10-16.

[12] N. L. Lugogo and M. Kraft "Epidemiology of Asthma," Clinics in Chest Medicine, Vol. 27, No. 1, 2006, pp. 1-15.

[13] D. Mannino, D. Homa, L. Akinbami, J. Moorman, C. Gwynn and S. Redd, "Surveillance for Asthma," United States, 1980-1999, MMWR Surveill Summ’02, Vol. 51, No. 1, pp. 1-13.

[14] K. B. Weiss and S. D. Sullivan "The Health Economics of Asthma and Rhinitis. I. Assessing the Economic Impact,” Journal of Allergy and Clinical Immunology, Vol. 107, No. 1, 2001, pp. 3-8.

[15] K. B. Weiss, P. J. Gergen and T. A. Hodgson, “An Economic Evaluation of Asthma in the United States," New
England Journal of Medicine, Vol. 326, No. 13, 1992, pp. 862-866.

[16] Massachusetts Department of Public Health, "First Statewide Pediatric Asthma Report Released.” http://www.mass.gov/dph/media/2004/pr0504.htm

[17] M. Lara, L. Akinbami, G. Flores and H. Morgenstern, "Heterogeneity of Childhood Asthma among Hispanic children: Puerto Rican Children Bear a Disproportionate Burden,” Pediatrics, Vol. 117, No. 1, 2006, pp. 43-53.

[18] D. R. Gold and R. Wright, "Population Disparities in Asthma,” Annual Review of Public Health, Vol. 26, 2005, pp. 89-113.

[19] National Center for Health Statistics Centers for Disease Control and Prevention, Summary Health Statistics for U.S. Children: National Health Interview Survey, 2002. In: Vital and Health Statistics, Department of Health and Human Services, Washington, DC, 2004.

[20] Boston Public Health Commission Research Office. Health of Boston 2002. Boston Public Health Commission, Boston, 2005.

[21] D. Buchwald, J. Goldberg, C. Noonan and J. Beals and S. Manson, "Relationship between Post-Traumatic Stress Disorder and Pain in Two American Indian Tribes," Pain Medicine, Vol. 6, No. 1, 2005, pp. 72-79.

[22] R. Wright, "Health Effects of Socially Toxic Neighborhoods: The Violence and Urban Asthma Paradigm," Vol. 27, No. 3, 2006, pp. 413-421.

[23] J. Gern, C. Visness, P. Gergen, et al. "The Urban Environment and Childhood Asthma (URECA) Birth Cohort Study: Design, Methods and Study Population,” BMC Pulmonary Medicine, Vol. 9, 2009, p. 17.

[24] P. Lehrer, S. Isenberg and S. Hochron, "Asthma and Emotion: A Review,” Journal of Asthma, Vol. 30, No. 1, 1993, pp. 5-21.

[25] S. Romagnani, "Induction of TH1 and TH2 Responses: A Key Role for the 'Natural' Immune Response?” Immunol Today, Vol. 13, No. 10, October 1992, pp. 379-381.

[26] R. J. Wright and S. F. Steinbach, "Violence: An Unrecognized Environmental Exposure that may Contribute to Greater Asthma Morbidity in High Risk Inner-City Populations,” Environmental Health Perspectives, Vol. 109, No. 10, 2001.

[27] P. G. Holt, "Immunoprophylaxis of Atopy: Light at the End of the Tunnel?” Immunol Today, Vol. 15, No. 10, 1994, pp. 484-489.

[28] A. Yabuhara, C. Macaubas, S. L. Prescott, et al., "TH2Polarized Immunological Memory to Inhalant Allergens in Atopics is Established during Infancy and Early Childhood," Clinical and Experimental Allergy, Vol. 27, No. 11, 1997, pp. 1261-1269.

[29] R. Wright, S. Weiss, S. Cohen, M. Hawthorne and D. Gold, "Life Events, Perceived Stress, Home Characteristics and Wheeze in Asthmatic/Allergic Families," American Journal of Respiratory and Critical Care Medicine, Vol. 153, 1996, p. A420.

[30] R. J. Wright, H. Mitchell, C. M. Visness, et al., “Com- 
munity Violence and Asthma Morbidity: The Inner-City Asthma Study," American Journal of Public Health, Vol. 94, No. 4, 2004, pp. 625-632.

[31] T. Lindhorst, B. Beadnell, L. J. Jackson, K. Fieland and A. Lee, "Mediating Pathways Explaining Psychosocial Functioning and Revictimization as Sequelae of Parental Violence among Adolescent Mothers,” American Journal of Orthopsychiatry, Vol. 79, No. 2, 2009, pp. 181-190.

[32] D. Finkelhor, H. Turner, R. Ormrod, S. Hamby and K. Kracke, "Children's Exposure to Violence: A Comprehensive National Survey,” Juvenile Justice Bulletin, 2009, pp. 1-10.

[33] K. Sheehan, J. A. DiCara, S. LeBailly and K. K. Christoffel, "Children'S Exposure to Violence in an Urban setting," Archives of Pediatrics and Adolescent Medicine, Vol. 151, No. 5, 1997, pp. 502-504.

[34] L. Taylor, B. Zuckerman, V. Harik and B. Groves, "Witnessing Violence by Young Children and Their Mothers," International Journal of Occupational Medicine and Environmental, Vol. 15, No. 2, 1994, pp. 120-123.

[35] R. J. Wright and S. F. Steinbach, "Violence: An Unrecognized Environmental Exposure that may Contribute to greater asthma morbidity in High Risk Inner-City Populaions,” Environmental Health Perspectives, Vol. 109, No. 10, 2001, pp. 1085-1089.

[36] M. P. Jensen, J. A. Turner, J. M. Romano and P. Karoly, "Coping with Chronic Pain: A Critical Review of the Literature,” Pain, Vol. 47, No. 3, 1991, pp. 249-283.

[37] R. F. Anda, J. B. Croft, V. J. Felitti, et al., "Adverse Childhood Experiences and Smoking during Adolescence and Adulthood," Journal of the American Medical Association, Vol. 282, No. 17, 1999, pp. 1652-1658.

[38] E. Aisenberg, "The Effects of Exposure to Community Violence upon Latina Mothers and Preschool Children," Hispanic Journal of Behavioral Sciences, Vol. 23, 2001, pp. 378-398.

[39] H. Foster and J. Brooks-Gunn, "Toward a Stress Process Model of Children'S Exposure to Physical Family and Community Violence," Clinical Child and Family Psychology Review, Vol. 12, No. 2, 2009, pp. 71-94.

[40] N. A. Ashford, "Implementing the Precautionary Principle: Incorporating Science, technology, fairness and accountability in Environmental, Health and Safety Decisions," International Journal of Occupational Medicine \& Environmental, Vol. 17, No. 1, 2004, pp. 59-67.

[41] D. I. Sheppard and S. Bilchik, "Promising Strategies to Reduce Gun Violence: Report,” Office of Juvenile Justice and Delinquency Prevention, Cosmos Corporation, Washington, D.C., United States, 1999.

[42] B. D. Smedley, A. Y. Stith and A. R. Nelson, "Institute of Medicine (U.S.). Committee on Understanding and Eliminating Racial and Ethnic Disparities in Health Care. Un- equal Treatment: Confronting Racial and Ethnic Disparities in Health Care,” National Academy Press, Washington, D.C., 2003.

[43] The Disparities Project, "Data Report: A Presentation and Analysis of Disparities in Boston,” Boston Public Health Commission, Boston, 2005.

[44] M. Viswanathan, A. Ammerman, E. Eng, et al. "Community-Based Participatory Research: Assessing the Evidence,” Agency for Healthcare Research and Quality, Rockville, 2004.

[45] R. D. Lasker and E. S. Weiss, "Broadening Participation in Community Problem Solving: A Multidisciplinary Model to Support Collaborative Practice and Research," Journal of Urban Health, Vol. 80, No. 1, pp. 14-47, 2003, pp. 48-60.

[46] P. J. Kelly, "Practical Suggestions for Community Interventions Using Participatory Action Research,” Public Health Nursing, Vol. 22, No. 1, 2005, pp. 65-73.

[47] K. Lapping, D. R. Marsh, J. Rosenbaum, et al. "The Positive Deviance Approach: Challenges and Opportunities for the Future,” Food and Nutrition Bulletin, Vol. 23, No. 4, 2002, pp. 130-137.

[48] D. R. Marsh and D. G. Schroeder, "The Positive Deviance Approach to Improve Health Outcomes: Experience and Evidence from the Field. Introduction," Food and Nutrition Bulletin, Vol. 23, No. 4, 2002, pp. 5-8.

[49] E. S. Tonorezos, P. N. Breysse, E. C. Matsui, et al. "Does Neighborhood Violence Lead to Depression among Caregivers of Children with Asthma?” Social Science and Medicine, Vol. 67, No. 1, 2008, pp. 31-37.

[50] J. Krieger and D. L. Higgins, "Housing and Health: Time Again for Public Health Action," American Journal of Public Health, Vol. 92, No. 5, 2002, pp. 758-768.

[51] J. Krieger, "Home Visits for Asthma: We Cannot Afford to Wait Any Longer," Archives of Pediatrics and Adolescent Medicine, Vol. 163, No. 3, 2009, pp. 279-281.

[52] J. D. Osofsky, "Children as Invisible Victims of Domestic and Community Violence,” In: G. W. Holden, R. Geffner, E. N. Jouriles, eds. "Children Exposed to Marital Violence: Theory, Research and Applied Issues,” American Psychological Association, Washington, DC, 1998, pp. 95-117.

[53] J. D. Osofsky, "The Effects of Exposure to Violence on Young Children,” American Psychologist, Vol.50, No. 9, 1995, pp. 782-788.

[54] N. Krieger, "Embodiment: A Conceptual Glossary for Epidemiology,” Journal of Epidemiology and Community Health, Vol. 59, No. 5, 2005, pp. 350-355.

[55] N. Krieger and G. Davey Smith "Bodies Count and Body Counts: Social Epidemiology and Embodying Inequality,” Epidemiologic Reviews, Vol. 26, 2004, pp. 92-103. 